\title{
Climate and Vegetation Change IN THE CENTRAL GRASSLANDS BIOGEOGRAPHIC AREA
}

\author{
GLENN E. Plumb $\downarrow$ UW/NPS RESEARCH CENTER \\ UNIVERSITY OF WYOMING $\bullet$ LARAMIE
}

\section{$\rightarrow \quad$ INTRODUCTION}

The purpose of this document is to describe the intent of climate change research being funded by the National Park Service (NPS) in the Central Grasslands (CEGR) Biogeographic Area (BGA). For the purposes of this document, the CEGR BGA is broadly defined as areas of historical or potential grassland extending from the southern Canadian provinces to northern Mexico and from the foothills of the Rocky Mountains to western Indiana. The majority of NPS units containing prairie within this BGA are short-grass, northern mixed-grass, or tall-grass ecosystems.

Increasing levels of atmospheric greenhouse gases ( $\mathrm{CO} 2, \mathrm{CH} 4, \mathrm{CFCs}$, etc.) are expected to induce dramatic changes in the world's climate over the next 30-100 years. General circulation model (GCM) simulations for a doubling of $\mathrm{CO} 2$ have projected 2-3xC increases in mean global temperatures and major transformations of land surface hydrology. Extensive modification of the land surface due to land use changes (e.g. deforestation, irrigation) are also anticipated to have important effects on atmospheric circulation and climate.

Because the climate of the North American CEGR BGA is strongly influenced by both the mid-latitude jet stream and circulation from the Bermuda subtropical high pressure center, projected changes in global circulation will likely result in a marked alteration of regional and local climates of the CEGR BGA. Such changes would have major consequences for the ecologic and hydrologic resources of the area. Climate change of this predicted magnitude would fundamentally influence the structure and function of ecosystems throughout the CEGR BGA, including NPS Parks and Monuments of the region. This influence would be felt through changes in the variability of climate, especially extreme conditions, as well as the means of climate. Both changes in means and extremes would entail changes in ecosystem function, the composition of ecosystems across park landscapes, and distributions of species across the region.

Plants provide most of the structure to terrestrial ecosystems so that the responses of plants to climate change and ecosystem feed-backs are central to predicting changes in parks. Therefore, a high priority for predicting the changes in habitat arrays and ecosystem functions in parks is to predict the distributional responses of plants to climate change. Anticipated changes in climate and direct $\mathrm{CO} 2$ effects will probably impact nearly all plant and animal species and communities in the CEGR BGA. Such changes will be most important for those restricted by limited range, small populations, and genetic isolation. High latitude, mid-continent ecotonal, and relict grassland landscapes are likely to provide early indications of climatic change. Thus, species and communities within NPS units may be especially sensitive because they are typically remnants of larger populations reduced by habitat loss. Direct effects will doubtless be further complicated by bio-feedbacks to the climate system.

The NPS is faced with future options varying from managing for grasslands in their present state, 
to mitigating change to grasslands expected under altered climatic and/or $\mathrm{CO} 2$ regimens. A goal of the NPS Global Change Program is to develop basic data for refining and validating models to predict ecosystem responses in a biogeographic area. Specifically, CEGR BGA research entitled: "Projecting climate and regetation change for the Central Grasslands Biogeographical Area, W.A Reiners, T.G.F. Kittel, R.A. Pielke, R.P. Neilson, and J.M. Lenihan, 1992-1997" integrates database development and simulation modelling and is directed toward a better understanding of the consequences of global change for geographic distributions and dispersal of life forms and species of the CEGR BGA. In brief, this research proposes to develop scenario-based predictions of climate and vegetation change for the CEGR BGA by linking mesoscale climate modeling with vegetation distribution modeling. This proposed research is organized as a three-team effort consisting of a coordination/data gathering team (Univ. of Wyoming), a mesoscale climate modelling team (Colorado State Univ.), and a vegetation change modelling team (Oregon State Univ.).

\section{$\checkmark \quad$ OBJECTIVES AND HYPOTHESES}

This research addresses the following questions: 1) What will be the nature of climate change for the CEGR BGA due to globally increasing levels of greenhouse gases?, 2) How will the ranges of dominant plant types change in response to climate change over the CEGR BGA?, and 3) How will the "natural" vegetation (excluding intensive agriculture) be altered at the landscape scale in NPS lands and other reserves, and how will that lead to biospheric feedback?

Hypotheses regarding future CEGR BGA climates will not be directly testable because of the 30-100 year time frame projected for such changes. Such hypotheses can instead be explored in a modelled environment by testing the sensitivity of a simulated climate to external forcing (i.e. the regional response to global change) or internal forcing (i.e. regional biosphere-climate feedbacks). Clearly, the success of such evaluations depends on how well a model simulates the real world.

GCM's for elevated levels of greenhouse gases helped generate several hypotheses that could be tested with meso-scale climate simulations. Thus, it can be hypothesized that surface temperatures will be higher across the CEGR BGA, with greater increases occurring in the northern part of the region than in the south. GCM simulations project increases in temperature to be larger at high latitudes than lower latitudes and that mid-continental North America will be drier. Thus, summertime precipitation across the Midwest should decrease. An alternate hypothesis is that greater increases in temperature in the continental interior relative to the Gulf of Mexico coast may enhance mid-continental monsoonal circulation and increase summer precipitation. In addition, meso-scale climate models will test whether winter to early-summer precipitation generated by mid-latitude cyclonic storms will increase due to the increased waterholding capacity of a warmer troposphere.

Modeling vegetation change is another key component of this research. A high priority for projecting the changes in habitat arrays and ecosystem functions in prairie parks will be to project how rapid climate may affect plant (life-form) distributions. Under $2 \times \mathrm{CO} 2$ scenarios: (1) desert shrub vegetation should develop in the southwestern portion of the present-day CEGR BGA; (2) short grass plains should expand eastward at the expense of present-day mid-grass and tall grass prairie; (3) northern mixed grasslands should expand into the present-day boreal forest of Canada; and (4) eastern deciduous forest in gallery forests of the CEGR BGA and the periphery of the region should be reduced in vigor and extent.

How will biospheric and vegetation change function as feedbacks to local and regional climates? Changes in vegetation type and cover may influence soil erosion, the local radiative environment, and land surface-atmosphere energy and moisture exchange. Changes in surface albedo and surface heat balance strongly influence meso-scale atmospheric circulation patterns and potentially, the generation of convective storms. Hypotheses will be evaluated using high spatial resolution Regional Atmospheric Modeling System (RAMS) simulations with surface characterization based on vegetation distribution simulated by the vegetation model under current and GCM-projected climates. 


\section{SIMULATION MODELLING}

Current projections for scenario-based climate changes are based on large-scale, coarse resolution GCM simulations carried out by a few major centers in the U.S. These have very coarse resolution (e.g., 4.5x latitude $\sim 7.5 x$ longitude, with $500 \mathrm{~km}$ horizontal grid interval at mid-latitudes) and provide inadequate prediction for climate variables for a specific region like the CEGR BGA and no statistical estimates of the distribution of heat and precipitation over a time period such as a month. This research proposes to "scale-down" from GCM scales to mesoscales in order to make more meaningful predictions for the CEGR BGA. To solve the problem of poor simulation, this research will generate fine-resolution (e.g., $40 \mathrm{~km}$ and for selected areas, $10 \mathrm{~km}$ grid intervals) regional simulations of climate change over the CEGR BGA.

In this research, a rapidly evolving modelling system (Mapped Atmosphere-Plant Soil System, MAPPS) will simulate biological constraints on what life form becomes dominant. These constraints include leaf area and stomatal controls on site water balance, as well as competition between woody and grass life forms for both light and water. The MAPPS model has been designed to simulate all upland vegetation types in the conterminous United States with regional to landscape resolution.

\section{CEGR BGA GLOBAL CHANGE RESEARCH PROGRAM MILESTONES}

The CEGR BGA program will be under the primary leadership of the CEGR BGA Coordinator /Unit Leader, located at the University of Wyoming Cooperative Parks Studies Unit (UW CPSU) who will be supervised by the Chief, Branch of Science, Rocky Mountain Region. As outlined in the discussion above, the research system of the CEGR BGA Global Change Research Program is strongly oriented towards the linkage of climate and vegetation modeling and long-term database development. This research plan is the spatially appropriate approach to examine the consequences of climate change on large geographic areas such as the CEGR BGA. Additionally, this program emphasis offers an excellent opportunity for the CEGR BGA Program to develop and contribute considerable expertise in meso- and land-scape modelling of climate, vegetation, and zoogeographic change to the National
Global Change Program. One of the most important goals of our research will be to strengthen the communication linkages between park units and the scientific community. To this end synthesis workshops, and park specific data and product delivery are integral components of the program.

This research is directed toward a coordinated modelling effort that will provide three products to NPS land managers: 1) mesoscale climate change predictions based on a range of reasonable but everchanging GCM scenarios, 2) regional vegetation change for the region which provides an ecological matrix for changes that might occur on particular land units, and 3) a modelling system that can be applied to particular land units that have sufficient spatially-arrayed data for prediction of vegetation and other ecological changes on a landscape scale.

In addition to producing annual and final reports, research milestones include 1) estimation of bounds of climate change (FY 93), 2) development and testing of alternative meso-scale climate change hypotheses based on additional GCM projections (FY 94), 3) begin re-scaling of meso-scale models to landscape models (FY 94), 4) continue testing alternative hypotheses and rescaling of landscape models (FY 95), 5) complete rescaling landscape model and application to two primary NPS units (FY 96), 6) test coupled climate/vegetation interaction models (FY 96), and 7) applications of simulation models to primary NPS sites (FY 95 and FY 96).

Delivery of research progress to park units will occur in the form of annual reports, annual research synthesis bulletins (2-5 pages) which summarize research reports, maps for use by park interpretation and resource management staff, and demonstrations of simulation models. The CEGR BGA Coordinator will be responsible to insure information transfer through a series of synthesis workshops described below. Contributions from CEGR BGA Program staff and research investigators are planned to enhance public understanding through popular articles and/or contributions to exhibits. Investigators will prepare briefings for presentation at annual synthesis workshops and will provide guidance and expertise through CEGR BGA Program staff in order to enable parks to prepare interpretive materials. 
This research program proposes to primarily service protected natural ecosystems in National Park Service units of the CEGR BGA in conjunction with Elk Island National Park of the Canadian Parks Service (CPS). There exists a generally east-west gradient reflecting greater habitat fragmentation in the east to relatively contiguous, drier, western grasslands. The range in size and spatial distribution of NPS units provides a partially balanced spatial network which recognizes the environmental and habitat fragmentation gradients. The NPS units are the most valuable resource for this program and so emphasis will be placed accordingly. Auxiliary corroborating sites that provide important spatial linkages unrepresented by NPS sites also will be included. The purpose of these auxiliary sites is to provide geographic and ecological balance, and opportunity for database development which facilitates program research goals. In recognition of the existing contributing databases and GIS capabilities, two NPS units are identified as primary sites (Indiana Dunes National Lakeshore and Wind Cave National Park). While all NPS CEGR BGA sites will receive products from meso-scale modelling efforts, the two primary sites have been identified for initial application of landscape scale simulation models. 